\title{
Current Situation and Research of the Asset Securitization of China
}

\author{
Bofan $\operatorname{Jin}^{1, \text { a }}$ \\ ${ }^{1}$ Department of Finance, Shanghai University, Shanghai, China, 200444 \\ a email
}

Keywords: Asset Securitization, Credit Enhance, Credit Asset

\begin{abstract}
Since China began the pilot asset securitization from 2005, its development has been slow and fluctuating. The most serious crisis affected by the U.S. subprime mortgage crisis forced the pilot breakdown for a long period. How to develop China's asset securitization is the core issue of China's finance. This paper discusses the current situation and problems of asset securitization in China, and gives the corresponding countermeasures and suggestions to provide some references for the related researchers.
\end{abstract}

\section{Current Situation of Asset Securitization of China}

Modern asset securitization originated from the mortgage-backed securities in the end of 1960s in the United States. Asset securitization refers to the originator will produce the expected cash flow of specific assets or portfolios, sold to a particular issuer, or the underlying asset trust to specific trustee, which generate cash flow to pay support through structured arrangement of credit the basic level, the asset securitization packaging, a financial instrument or document of title and form issued to investors, and provide the open place for investors, such as the inter-bank bond market and stock exchange. Credit enhancement may be provided by internal credit enhancement and external credit enhancement, internal credit enhancement including but not limited to the excess mortgage hierarchy of asset-backed securities and cash collateral accounts spread account etc., external credit enhancement including but not limited to the standby letter of credit guarantees and insurance, commercial banks to provide credit enhancement for credit asset securitization transactions. Most of the credit asset securitization products adopt asset-backed securities in the form of hierarchical structure. This is intended to encourage the implementation of the bank asset securitization, the new regulations significantly reduces the minimum grade retention rate, the real implementation of the bank's capital saving, capital consumption will be significantly improved, will promote the asset securitization enthusiasm, revitalize the stock, accelerate the credit asset turnover. The commission canceled the administrative examination and approval procedures of the special asset management plan.

\section{Existing Problems of the Development of Asset Securitization of China}

Imperfection of Law System. I In order to ensure the standardization and healthy development of China's asset securitization, it is necessary to develop a scientific judicial framework and create a suitable legal environment. One of the biggest obstacles in the developing countries is that the legal framework of the state judiciary is not suitable for all kinds of legal relations needed for asset securitization. Asset securitization is an important financial innovation, is produced in the framework of the legal system under the specific, but the development of asset securitization in turn to form the new legal system needs, promote the transition of the legal system. The asset securitization development, standardize and safeguard function cannot do without the legal system: 
the design of the framework for securities transactions need legal support and standardize the cost and efficiency of securitization will be affected by the legal system, the related assets and the service performance of the contract and the securitization of the parties in the securitization of rights the protection of the law and so on. Under the current situation of our country, we still do not recognize the form of limited partnership in the legal system of our country. Although the credit asset securitization, the basic legal framework of credit assets and non-performing asset securitization has been initially formed, the basic solution of credit assets and asset securitization issuance and actual operations involving property registration, accounting, information disclosure, tax management and other issues, provide the institutional foundation for more complete securitization of credit assets and bad assets. However, due to no asset securitization legislation, the relevant provisions of the bank credit asset securitization have some conflicts with the highest level law.

Singleness of Assets Classes. The primary premise of the development of asset securitization in our country is to ensure the financial security, it is necessary for China's market environment, but it is also because of this carefully, to some extent limit the pace of development of asset securitization in china. At present our country has been in the pilot asset securitization products mainly include three categories: the commission management of the enterprise asset securitization products, approved by the CBRC and the central bank's credit asset securitization and securitization of non-performing assets, more than three accounted for the total size of the current market share of the vast majority. While China's current capital market in addition to the stock market, others such as the real estate mortgage market and bank accounts receivable accounts receivable and credit card market is not developed. On the essence of asset securitization, the requirement must be to build a pool of assets on the basis of homogeneity, that is, a basket of assets in the pool of assets should be a basket of assets should have a similar income and risk. But in fact, the asset securitization of our country in the construction of the asset pool was not standardized. The choice of assets are diversified, including electric power, telecommunications, infrastructure and media industries, then the pricing time would inevitably produce a lot of problems. The development of asset securitization market depends on its supply and demand. In the supply side, there must be enough to choose the securitization of assets. But at present our country can be used for the securitization of assets has not formed the scale advantage, can produce the future stable cash flow quantity of assets is also relatively small, the level of the market is not developed.

Shortage of Credit Rating. Throughout the process of asset securitization involves a lot of intermediary services, including the most important credit rating agencies and credit enhancement agencies. However, the current credit rating system of China's financial securities industry operation is not standardized, there is no unified evaluation standard, and assessment agencies strength is weak and lack of credibility rating structure is difficult to obtain the majority of investors agree. Compared to the financial intermediaries in China and mature capital market and its development level is still relatively low, especially the development of the credit rating agencies, not only the lack of technology and talent assessment at the present stage of China's financial intermediation in the credit function classification and credit rating, but the development is still a foreign type exploration stage, but the main structure of credit our country and the institutional environment and mature market countries differ greatly, so these problems are restricting the development of China's asset securitization. Credit rating agencies in the operation of asset securitization is very important, only after the credit rating agencies of the strict credit rating after the securitization products can be successfully issued. However, Chinese current credit rating system of the overall level of development is very limited, the current domestic large credit rating 
agencies only four, while the credibility is very low. But with the continuous accumulation of credit rating agencies of reputation capital, get a credit rating, for financial market financing body becomes increasingly important and the popularization of information technology makes the rating report is released, the business model to subscribe to the user fee cannot continue. Therefore, become the main source of profit income rating agencies to evaluation rating fees charged. The transformation of the business model has its rationality and inevitability, but this model also has drawbacks, which is very easy to lead to conflicts of interest.

\section{Countermeasure Proposals of the Development of Asset Securitization of China}

Improve Legal System. In order to realize the flying over of China's asset securitization and solve the legal risks faced by investors, it is a fundamental requirement to unify the legislation of asset securitization. There is no unified legal system, China's asset securitization is bound to exist in the development of disorder, and regulate the weak situation. Because of the complexity of the existing legal system, many conflicts and asset securitization laws are enacted by the National People's Congress and its Standing Committee, and to modify these legal provisions, must be the same by the NPC and its Standing Committee to carry out. Therefore, it is very difficult to find out all the legal provisions related to asset securitization and make it one by one, and even if it does, it is not economical in the legislation. In this case, this paper argues that the reference to foreign legislative model of asset securitization legislation, the establishment of unified issuance and listing, trading rules, the establishment of specialized asset securitization unified legal system. In addition to the asset securitization and makes a comprehensive and systematic specification, but also in conflict with the asset securitization law in the provisions of the exception clause, to solve the problem of legal obstacles to the development of asset securitization through these exceptions. Because the process of asset securitization is to many participants, especially which will involve accountants, appraisers and lawyers and other professionals, is more complex than most other financial transactions, such as securitization has many procedures for examination and approval and licensing system, accounting and tax system, information disclosure and supervision system and other issues need to solve the law. Therefore, we should make a research on asset securitization special laws and regulations to promote the rapid development of information.

Enrich Asset Variety. China has carried out the individual housing mortgage loan, the infrastructure in the long-term loan securitization pilot. Chinese government is vigorously developing the infrastructure construction, the need for long-term capital investment, capital turnover time is longer, if a single government or banks are difficult to meet, and asset securitization can solve these problems. Through the pilot work, can reduce the cost of financing, ease the liquidity risk of banks, improve bank capital turnover rate. Vigorously promote the development of asset securitization market, to provide a broad space for the development of financial innovation, improve the financial environment in china. We should vigorously develop the capital market, and actively develop asset securitization products, the establishment of a market driven variety of innovative mechanisms. For a country with a high savings rate, we should look for better investment products, explore more securitization products, and promote the development of asset securitization. Further promote asset securitization pilot, lessons learned from the U.S. subprime mortgage crisis, can make China's asset securitization less detours. But at the same time, the demand for funds is difficult to supply, therefore, could be considered to be the small and medium-sized enterprise credit asset securitization to provide more funds for small and medium-sized enterprises, which can effectively help solve the financing problems of SMEs in china. Then according to the agriculture related loans and infrastructure project loans at present the 
national priority areas in support of the credit asset securitization, increase support for key areas of credit and gradually expand the scope of basic assets.

Cultivate Crediting Organization. The development of the social credit environment will directly restrict the asset securitization. Credit rating agencies play in the process of asset securitization is an important role in this, rating agencies first to assess the risk of assets on the basis of itself. We must keep track of its credit rating in the securities issued, and constantly updated until the maturity of securities credit rating. Credit rating agencies have played a role in enhancing market transparency, protecting the interests of investors and maintaining market confidence. Therefore, the healthy development of the asset securitization market is the low level of credit rating agencies. And it is the United States advanced credit rating system and its importance to the credit rating of this concept to a large extent contributed to the development of its asset securitization. We must strengthen the information disclosure of asset securitization and set up credit rating agencies and credit enhancement mechanism, but also to prevent the over reliance on credit rating agencies, the appropriate rating agencies to strengthen penalties and dereliction of duty illegal efforts. In view of China's assets and credit rating agencies in a small number, assessment of the quality is not high, the establishment of an international influence and authority of the assets and credit rating agencies is imperative. At the same time, these agencies deal with unified management, make it play a role, not by other factors, objective and impartial assessment work; should learn from other countries mature experience rating system, using legal means to cut between assessment agencies and assessed the relationship, and ultimately enhance the prestige of our country's credit rating agency.

\section{Conclusion}

Due to the late start of asset securitization in our country, the experience is relatively insufficient. In the period of the United States finance crisis in 2008, Chinese asset securitization is suspended for three years. But we still have reason to believe that the asset securitization in our country will also have a good development to make a positive contribution to the economic development of China.

\section{References}

[1] Liu Yuangen, Economic Research Guide, Vol. 9(2013) No 5, p.73-74

[2] Zhang Ming, Zhou Xiaomei, Gao Bei, Shanghai Finance, Vol. 24(2013) No 11, p.31-36

[3] Zhang Xiaojing, Financial View, Vol. 18(2013) No 9, p.12-13

[4] Wu Ganping, Finance Economy, Vol. 33(2014) No 10, p.136-137 